\title{
A scientific note on rare parasitism of the bumble bee pollinator, Bombus impatiens, by a mermithid nematode, Pheromermis sp. (Nematoda: Mermithidae)
}

\author{
Sujaya RAO ${ }^{1}$, George PoInAR ${ }^{2}$, David HenLEY ${ }^{3}$ \\ ${ }^{1}$ Department of Crop and Soil Science, Oregon State University, 3017 Agricultural and Life Science Building, Corvallis, OR \\ 97331, USA \\ ${ }^{2}$ Department of Integrative Biology, Oregon State University, 3029 Cordley Hall, Corvallis, OR 97331, USA \\ ${ }^{3}$ East Middlesex and Suffolk County Mosquito Control Projects, 11 Sun St., Waltham, MA 02453, USA
}

Received 19 January 2016 - Revised 8 March 2016 - Accepted 12 May 2016

bumble bee / pollinator / parasitism / nematode

Nematodes in the family Mermithidae are parasites of diverse insects, spiders, leeches, and other invertebrates worldwide (Nickle 1972). Insects are the most common hosts, and at least 15 insect orders are parasitized by mermithids. Parasitism by mermithids is usually fatal to the host, and hence, mermithids have been considered as potential biological control agents for pest species such as yellow jackets, Vespula spp. and hornets, Vespa spp. (Moller et al. 1991; Martin 2004; Villemant et al. 2015). However, mermithids can also parasitize beneficial insects such as insect pollinators. Honey bees, Apis mellifera L., were reported to be parasitized by the mermithid Agamomermis sp. in Ithaca, New York (Morse 1955), and by Mermis subnigrescens Cobb in Urbana Champagne in IL (Milum 1938). M. subnigrescens is, however, a parasite of grasshoppers (Nickle 1972), and hence, the identity of this nematode needs confirmation. Less is known about mermithid associations with bumble bee pollinators. A single unidentified bumble bee was observed to be parasitized by an unknown mermithid in Lafayette, Indiana (MacLean 1966).

Here, we present the first report of mermithid parasitism of the bumble bee pollinator Bombus impatiens

Corresponding author: S. Rao,

Sujaya@oregonstate.edu

Manuscript editor: James Nieh
Cresson. In July 2015, dead bumble bees were observed under trees of little leaf linden (Tilia cordata Mill.; family Tiliaceae) in the town of Wakefield, MA, in eastern USA. There was an interest in determining the basis for the bumble bee deaths as mortality of bumble bees associated with linden trees treated with neonicotinoid insecticides has been reported annually in the USA since 2013 (Argoti and Rao 2015). Besides neonicotinoids, other factors such as nectar toxins are speculated to kill bumble bees foraging on linden (Crane 1977; Rao 2016) while pathogens and parasites have been implicated in recent bumble bee population declines (Cameron et al. 2011).

For analysis of potential mortality factors of bumble bees collected in Wakefield, 68 dead bumble bees were shipped to the Oregon State University where each bee was regurgitated for analysis of nectar and then dissected for detection of pathogens and parasites. In one worker B. impatiens, a single white nematode (Figure 1) was observed coiled inside the abdomen, nearly filling it. The host bumble bee looked like all others in the shipment, and there was no external indication that the bee was parasitized. The nematode was preserved in $30 \%$ ethyl alcohol, fixed in $5 \%$ formalin, and processed to glycerin for further study. The specimen is $46 \mathrm{~mm}$ in length and $40 \mu \mathrm{m}$ in greatest width. It aligns with Pheromermis sp. based on the presence of the following characters: cuticle with cross fibers, no lip papillae, four cephalic papillae in submedial positions, cup-shaped amphids placed anteriorly, ventrally 


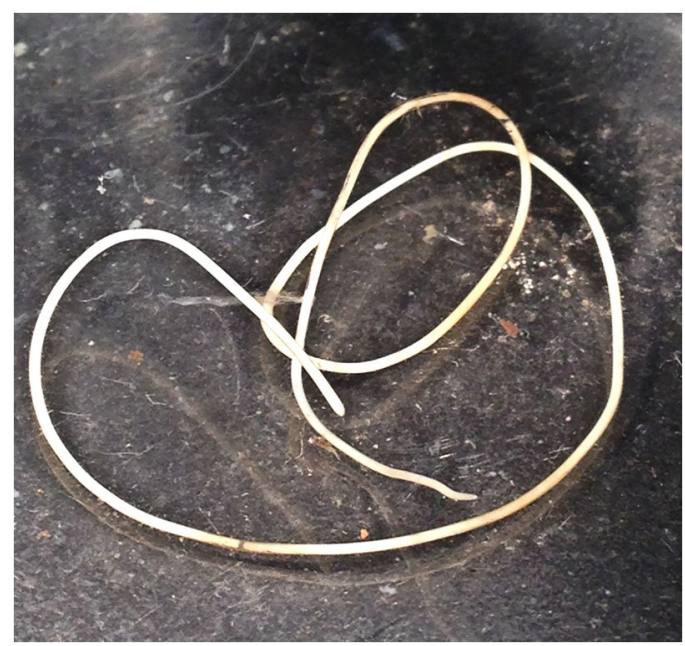

Figure 1. Mermithid parasite recovered from a dead Bombus impatiens worker collected under a linden tree in Wakefield, MA, USA.

displaced mouth opening, and no cuticular projection on tail. Without the adult stage, it is not possible to confidently assign the bumble bee mermithid to a species, and it could represent an undescribed species.

Pheromermis spp. are parasites of yellow jackets in North America and Europe with a unique life cycle (Poinar 1981; Kaiser 1987). Typically, mermithid nematodes develop in a single host. However, in Pheromermis spp., a second paratenic or transport host is involved (Poinar et al. 1976). The paratenic host becomes infected when eggs that are laid in or near water sources are ingested (Molloy et al. 1999). The eggs hatch in the host midgut, and the emerging juveniles penetrate the peritrophic membrane to enter the hemocoel. They migrate to various tissues such as the gut epithelium, hypodermis, muscle, connective tissue, and fat bodies, where they coil and remain quiescent. Multiple juveniles can be present in a single paratenic host. They remain viable throughout the life of the paratenic host even during its metamorphosis to the adult stage. They do not develop further and cause minimal damage to the paratenic host. The eggs cannot hatch in the gut of an adult wasp, and hence, the paratenic host is an obligatory step in the life cycle of the Pheromermis nematodes. When an infected adult is caught by a yellow jacket or hornet and fed to its larva, the nematodes become active and feed on non-vital tissues of the immature wasp but rarely kill the host. The adult wasp emerges and the mermithid matures in its abdomen. It does not kill the adult right away but causes sterility in both males and females (Poinar et al. 1976). When the infected wasp visits a water source, the mature Pheromermis leaves its host, which it kills in the process, molts into the adult stage, mates and lay eggs, and thus completes the life cycle.

In the mermithid-parasitized bumble bee collected in the current study, the infection route is not known. The bumble bee could have acquired a Pheromermis egg while seeking a water source. Based on the large size and location of the mermithid, it must have developed in the bumble bee, in which case, this would be the first report of Pheromermis developing in hosts other than Vespa spp. or Vespula spp., and having no paratenic host! It is possible that the mermithid could represent a new species of Pheromermis that is adapted to bumble bees. Future recoveries of mermithids from bumble bees are needed for further insights of the mermithidbumble bee parasitism observed in the current study.

The bumble bee $B$. impatiens is a common native pollinator in eastern USA (Colla et al. 2011) though commercial colonies are also placed in agricultural fields for augmenting crop pollination. In a 2-year survey of bumble bee parasites in western MA in eastern USA, $>1000$ bumble bees, including 574 B. impatiens workers and males were dissected for detection of natural enemies. Conopid parasitoids and the pathogens Crithidia bombi Gorbunov (Kinetoplastida: Trypanosomatidae) and Nosema bombi Fantham and Porter (Microsporidia: Nosematidae) were detected in nine bumble bee species including $B$. impatiens (Gillespie 2010). No mention was made of mermithids or of Sphaerularia bombi Dufour, a nematode that has been detected in other regions in the USA (Poinar and van der Lann 1972; Maxfield-Taylor et al. 2011). While $S$. bombi is a common nematode parasite of bumblebees, mermithid parasitism of bumble bees is rare and has been reported earlier only once (MacLean 1966).

The current detection of the mermithid in a bumblebee may be a rare event. It may represent a new Pheromermis species with a different life history or adaptation and evolution of Pheromermis spp. that infect Vespa and Vespula spp. to a new host which differs greatly in feeding habits compared to the original wasp host. Our detection of the mermithid is of concern as $B$. impatiens is an important pollinator in eastern USA, and pathogens and parasites have been implicated in recent reports of bumble bee declines (Cameron et al. 2011). Mermithid infections are typically fatal to the host (Poinar et al. 1976), thus Pheromermis infections 
can negatively impact bumble bee pollinator populations. Hence, more research is needed to determine the life cycle of the mermithid detected in the current study, and its prevalence within bumble bee populations.

\section{ACKNOWLEDGMENTS}

The authors thank Nadine Wade for initial identification of the nematode as a mermithid, and Gracie Galindo for assistance with dissection of the bumble bees.

Note scientifique sur un cas rare de parasitisme du bourdon pollinisateur, Bombus impatiens, par un nématode, Pheromermis sp. (Nematoda: Mermithidae)

\section{Eine wissenschaftliche Notiz über seltene Parasitierung der Hummelbestäuberart Bombus impatien s durch einen Nematoden, Pheromermis sp. (Nematoda: Mermithidae)}

\section{REFERENCES}

Argoti, A., Rao, S. (2015) Why do bumble bees die after foraging on linden trees? Res. Rep. 74th Annu. Pacific Northwest Insect Manag. Conf., Portland OR, USA, pp: 25-26

Cameron, S.A., Lozier, J.D., Strange, J.P., Koch, J.B., Cordes, N., et al. (2011) Patterns of widespread decline in North American bumble bees. Proc. Natl. Acad. Sci. 108, 662-667

Colla, S., Richardson, L., Williams, P. (2011) Guide to the bumble bees of the eastern United States. USDA Forest Service and the Pollinator Partnership FS 972. http://www.fs.fed.us/wildflowers/pollinators/documents/BumbleBeeGuide2011.pdf

Crane, E. (1977) Dead bees under lime trees. Bee World 58, 129-130

Gillespie, S. (2010) Factors affecting parasite prevalence among wild bumblebees. Ecol. Entomol. 35, 737-747

Kaiser, H. (1987) Biologie, Okologie und Entwicklung des europaischen Wespen-Parasitoiden Pheromermis vesparum n. sp. (Mermithidae, Nematoda). In: Zoologische Jahrbucher. Abteilung fur Systematik, Okologie und Geographie der Tiere. Jena: G. Fischer

MacLean, B.K. (1966) Internal parasitism of Bombus spp. in Indiana. Proc. North Central Br. Entomol. Soc. Amer. 20, 94-95

Martin, S.J. (2004) A simulation model of biological control of social wasps (Vespinae) using mermithid nematodes. New Zeal. J. Zool. 31, 241-248

Maxfield-Taylor, S., Rao, S., Skyrm, K.M. (2011) A scientific note on the first record of Sphaerularia bombi (Nematoda: Tylenchida: Sphaerularidae), a parasite of bumble bee queens, in the Pacific Northwest. Pan Pac. Entomol. 87, 136-139

Milum, V.G. (1938) A larval mermithid, Mermis subnigrescens Cobb as a parasite of the honeybee. J. Econ. Entomol. 31 , 460

Moller, H., Wharton, D.A., Tyrrell, C. (1991) Pheromermis nematodes as biological control agents for the reduction of wasp abundance in New Zealand. Contr. Rep. Dept. Conserv. $49 \mathrm{p}$

Molloy D.P., Vinikour W.S., Anderson R.V. (1999). New North American records of aquatic insects as paratenic hosts of Pheromermis (Nematoda: Mermithidae). J. Invertebr. Pathol. 74, 89-95

Morse, R. (1955) Larval nematode recorded from honeybee Apis mellifera L. J. Parasitol. 41, 553

Nickle, W.R. (1972) A contribution to our knowledge of the Mermithidae (Nematoda). J. Nematol. 4, 113-146

Poinar, G.O. (1981) Distribution of Pheromermis pachysoma (Mermithidae) determined by paratenic invertebrate hosts. J. Nematol. 13, 421-424

Poinar, G.O., van der Lann, P.A. (1972) Morphology and life history of Sphaerularia bombi . Nematologica 18, 239-252

Poinar, G.O., Lane, R.S., Thomas, G.M. (1976) Biology and redescription of Pheromermis pachysoma (v. Linstow) n. gen., n. comb. (Nematoda: Mermithidae), a parasite of yellow jackets (Hymenoptera: Vespidae). Nematologica 22, 360-370

Rao, S. (2016) Mortality of bumble bees associated with linden: a review. Res. Rep. 75th Annu. Pac. Northwest Insect Manag. Conf., Portland OR, pp 36-37

Villemant, C., Zuccon, D., Rome, Q., Muller, F., Poinar, G.O., et al. (2015) Can parasites halt the invader? Mermithid nematodes parasitizing the yellow-legged Asian hornet in France. Peer J. . doi: 10.7717 peerj.947 